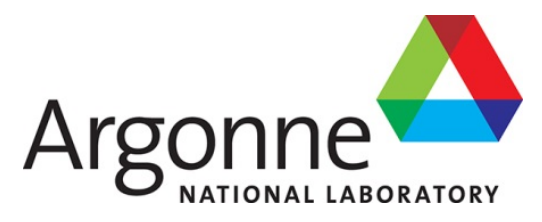

\title{
Calculation of Friction Factors in Heat Pipes Using CFD in Support of the Sockeye Code
}

Nuclear Science and Engineering Division 


\section{About Argonne National Laboratory}

Argonne is a U.S. Department of Energy laboratory managed by UChicago Argonne, LLC under contract DE-AC02-06CH11357. The Laboratory's main facility is outside Chicago, at 9700 South Cass Avenue, Argonne, Illinois 60439. For information about Argonne and its pioneering science and technology programs, see www.anl.gov.

\section{DOCUMENT AVAILABLITY}

Online Access: U.S. Department of Energy (DOE) reports produced after 1991 and a growing number of pre-1991 documents are available free at OSTI.GOV (http://www.osti.gov/), a service of the US Dept. of Energy's Office of Scientific and Technical Information.

Reports not in digital format may be purchased by the public from the National Technical Information Service (NTIS):

U.S. Department of Commerce

National Technical Information Service

5301 Shawnee Rd

Alexandria, VA 22312

www.ntis.gov

Phone: (800) 553-NTIS (6847) or (703) 605-6000

Fax: (703) 605-6900

Email: orders@ntis.gov

Reports not in digital format are available to DOE and DOE contractors from the Office of Scientific and Technical Information (OSTI):

U.S. Department of Energy

Office of Scientifice and Technical Information

P.O. Box 62

Oak Ridge, TN 37831-0062

www.osti.gov

Phone: (865) 576-8401

Fax: (865) 576-5728

Email: reports@osti.gov

\section{Disclaimer}

This report was prepared as an account of work sponsored by an agency of the United States Government. Neither the United States Government nor any agency thereof, nor UChicago Argonne, LLC, nor any of their employees or officers, makes any warranty, express or implied, or assumes any legal liability or responsibility for the accuracy, completeness, or usefulness of any information, apparatus, product, or process disclosed, or represents that its use would not infringe privately owned rights. Reference herein to any specific commercial product, process, or service by trade name, trademark, manufacturer, or otherwise, does not necessarily constitute or imply its endorsement, recommendation, or favoring by the United States Government or any agency thereof. The views and opinions of document authors expressed herein do not necessarily state or reflect those of the United States Government or any agency thereof, Argonne National Laboratory, or UChicago Argonne, LLC. 
ANL/NSE-20/47

Calculation of Friction Factors in Heat Pipes Using CFD in Support of the Sockeye Code

prepared by

Dillon Shaver and Adrian Tentner

Nuclear Science and Engineering Division, Argonne National Laboratory

August 28, 2020 


\section{Contents}

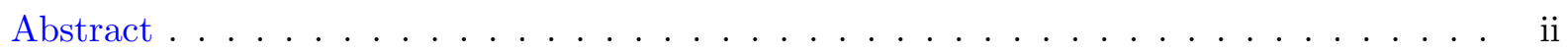

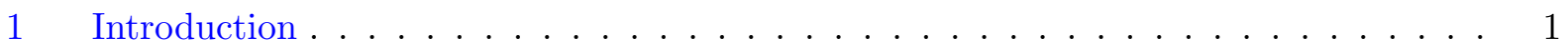

2 Model Description . . . . . . . . . . . . . . . . . . . . 2

2.1 Heat pipe model . . . . . . . . . . . . . . . . 2

2.2 Porous media model in Nek5000 . . . . . . . . . . . . . . . . 4

$3 \quad$ Results . . . . . . . . . . . . . . . . . . . . . . 4

3.1 Impact of wick permeability . . . . . . . . . . . . . . 5

3.2 Impact of wick saturation $\ldots \ldots \ldots \ldots \ldots \ldots$

4 Summary and Conclusions . . . . . . . . . . . . . . . . . . . . . 15

Acknowledgments . . . . . . . . . . . . . . . . . . . 16

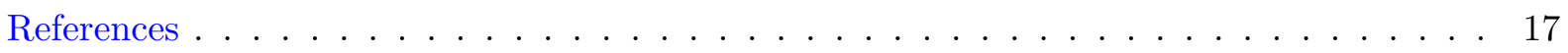




\section{Abstract}

A heat pipe is two-phase heat transfer device which relies on surface tension and capillary pressure to provide a very efficient heat transfer mechanism. Currently, there is interest in designing micro nuclear power reactors using high temperature heat pipes to provide totally passive cooling. To support this, Sockeye is being developed as a heat pipe simulation capability. To support the development of Sockeye, individual phenomena must be tested. This work focuses on applying a CFD model to evaluate friction factors for use in Sockeye.

A CFD model has been developed in Nek5000 which simulates each component fluid, i.e. sodium liquid and vapor, independently and captures the effects of the wick on friction factor. The model tests the effect of the wick permeability and the thickness of the wick occupied by each fluid component. The thickness of the wick occupied by each component can be directly related to the local vapor volume fraction from the Sockeye heat pipe model. Results from the CFD model indicate that friction factor in the liquid flow decreases with increasing wick permeability, while the friction factor in the vapor flow increases with increasing wick permeability. In the liquid, this is likely a direct result of the increased cross sectional area available for the flow. For the vapor, this is explained as the wick acting like a rough wall, while the increased area has only a negligible impact. Results for the tests of the thickness of the wick occupied by each fluid showed a thresholding behavior for both liquid and vapor. When the thickness of the wick occupied by each fluid was increased, it increased the effect of the wick, but only up to a certain point. Once a certain thickness was reached, the friction factors remained constant. When the fluid occupied only a very small fraction of the wick, friction factors returned to nominal values. 


\section{Introduction}

Liquid metal heat pipes are being considered in the design of simpler, safer, and more reliable small nuclear reactors, so-called micro-reactors. A schematic of a typical heat pipe is shown in Figure 1. Heat pipes are an attractive option due to their ability to "passively" transfer significant amounts of heat. Heat-pipe-cooled reactors can avoid many of the complex issues arising from the operation traditional reactor concepts such as coolant pumps. The key to the operation of a heat pipe is the wick, which can be seen in the schematic. The wick acts to enhance the movement of the working fluid, resulting in improved heat transfer. There is considerable operational knowledge on the use of heat pipes for various applications, however a comprehensive mechanistic based model is currently lacking.

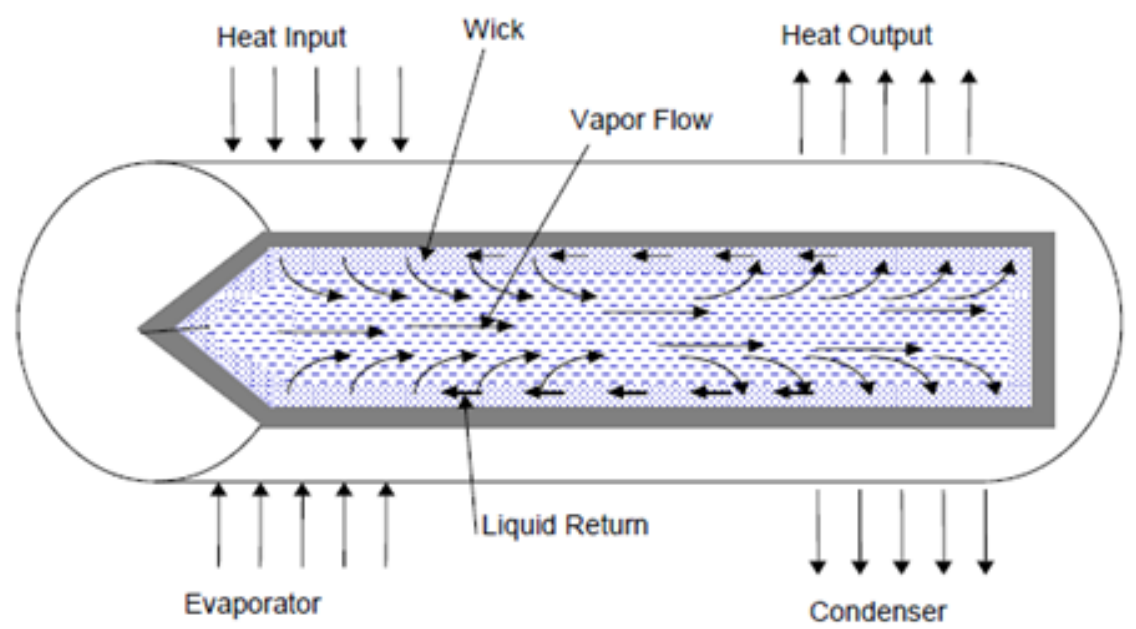

Figure 1: Heat pipe schematic

In order to aid in the design of micro-reactors, the Sockeye code is being developed by the NEAMS program [1]. Sockeye aims to provide the ability to accurately simulate heat pipe dynamics, while remaining computationally affordable enough to use for reactor design applications. To that end, several modeling areas are being investigated to support the development of Sockeye.

Three principal areas of investigation have been identified for Sockeye. These are the evaluation of models for capillary pressure, interfacial heat transfer, and friction factors. The evaluation of capillary pressure and interfacial heat transfer models requires either separate effects testing, or a robust fully resolved heat pipe simulation capability. For either scenario, there is a dearth of available experimental data for model validation. Previous efforts with Nek-2P showed promise at the development of a full heat pipe simulation capability [2], however it still requires significant development. The objective of this work is to develop a CFD model which can be used to analyze the effect of the wick on the expected wall-friction pressure associated with the individual phasic flows, i.e. liquid and vapor, in a typical liquid metal heat pipe. 


\section{Model Description}

\subsection{Heat pipe model}

In the Sockeye heat pipe model, the liquid and vapor phases are treated as $1 \mathrm{D}$ counter flowing channels. In a typical two-phase flow, the volume fraction is a local quantity representing the time or ensemble average of the phase indicator function. In the counter flowing channel model, however the volume fraction is interpreted as varying the radial location of the interface between the two phases. As a consequence, this allows each phase to be modeled independently as a 1D single phase channel.

To account for the pressure drop due to flow of the liquid and vapor, a simple friction factor model is currently used in Sockeye where the friction factors are given as inputs from the user and are assumed to be constant[1]. The force on each phase due to friction with the wall is then calculated using the Darcy-Weisbach equation

$$
F_{k}^{\text {wall }}=\frac{1}{2} \frac{f_{k} \rho_{k}\left|u_{k}\right| u_{k}}{D_{h, k}}
$$

where $f_{k}$ is the Darcy friction factor and the subscript $k$ implies that a quantity is defined for each phase. The hydraulic diameters are given by

$$
D_{h, v}=D_{w i c k, i}
$$

and

$$
D_{h, l}=\frac{4\left(\epsilon A_{w i c k}+A_{g a p}\right)}{\pi D_{h p, i}}
$$

These imply that wall friction in the vapor core is caused by contact with the inner surface of the wick, but for the liquid only the external wall is accounted for. The friction due to the flow through the porous wick is accounted for separately. However, this is a static model that does not account for the variability of the location of the interface within the wick. The penetration of each phase into the wick can have a substantial impact on the overall pressure drop.

In the proposed Nek5000 model, the effect of the wick on each phase is accounted for by explicitly including a porous media region. The vapor core is modeled as flow in a pipe with a thin porous region on the external wall. The liquid flow is modeled as flow in an annulus with a relatively thick porous region on the internal wall. The effect of the porous region on pressure drop is then tested for various permeabilities and thicknesses. The variable thickness mimics the effect of the variable radial location of the interface in the heat pipe model.

Heat pipe geometries and operating conditions are expected to vary significantly, but for micro-reactor applications, these are more focused on the following ranges:

- 1 - $5 \mathrm{~kW}$ power

- 900 - $1500 \mathrm{~K}$ operating temperature 
- 7 - 15 mm inner diameter

- $0.1-0.5 \mathrm{~mm}$ wick thickness

- 0.2 - $1.0 \mathrm{~mm}$ gap thickness

- Liquid metal working fluid

Note that these values are approximate and are only intended to provide a point of reference for the relevant region of interest.

The permeability of the wick is also highly variable and depends on the chosen wick type and material. For example, a metallic foam or a cloth-like mesh can be used. Currently, the permeability in Sockeye is provided as an input by the user [1]. The permeability has a significant direct impact on the friction pressure drop for both phases. It's effect is evaluated parametrically in the proposed Nek5000 model.

Once the geometry of the heat pipe has been chosen, the flow rates and parameters necessary for the Nek5000 model can be obtained. The flow rate is estimated from the simple first-principle mass-energy balance

$$
\dot{m}=\frac{\dot{Q}}{h_{f g}}
$$

At steady state operating conditions, both liquid and vapor will have the same total flow rate. To establish the relevant scaling, flow through the wick will be neglected. This lead to the following expressions for the phasic mass fluxes

$$
\begin{aligned}
G_{v} & =\frac{\dot{m}}{A_{\text {core }}} \\
G_{l} & =\frac{\dot{m}}{A_{\text {gap }}}
\end{aligned}
$$

and the Reynolds numbers are given as

$$
\begin{aligned}
R e_{v} & =\frac{G_{v} D_{w i c k, i}}{\mu_{v}} \\
R e_{l} & =\frac{G_{l} D_{h, g a p}}{\mu_{l}}
\end{aligned}
$$

The vapor uses the same hydraulic diameter as the Sockeye model, the inner wick diameter. The liquid, however, uses the hydraulic diameter for the annulus defined by the outer heat pipe wall and the outer wick diameter. These were chosen as the reference lengths in order to simplify the overall model. By reducing each phasic flow to the canonical problems of flow in a pipe and flow in a annulus, obtaining reference friction factors becomes much easier. 


\subsection{Porous media model in Nek5000}

The wick is accounted for by using the porous media model in Nek5000. This is incorporated as a body force in the momentum equation,

$$
\vec{F}_{k}=-\frac{\mu_{k}}{\epsilon \rho_{k}} \vec{u}_{k}
$$

which is implemented implicitly in the Helmholtz solver. This model has previously been used to model the flow into gaps between graphite reflector blocks in a pebble bed FHR [3]. In this work, the porous media model is activated on a per-element basis. This eliminates numerical oscillations in the solution associated with sharp transitions, but requires that the wick be conformal to the mesh.

Turbulence in the vapor core is simulated in Nek5000 using a RANS $\kappa-\tau$ model [4]. where $\kappa$ is the turbulent kinetic energy and $\tau$ represents the period of turbulent dissipation. The period of turbulent dissipation is analogous to the inverse of the turbulent dissipation frequency, represented by $\omega$ in the more popular $\kappa-\omega$ class of turbulence models. However it has the advantage of a simple zero Dirichlet wall boundary condition which can be easily implemented in the spectral element method. This model has been shown to produce results identical to the regularized $\kappa-\omega$ model that has been developed for Nek5000 [5].

It is assumed the wick will have a significant dampening effect on turbulence as reported in [6]. This is included in the porous media model as sink terms in the both the turbulent kinetic energy and dissipation period equations

$$
\begin{aligned}
& \rho \frac{D \kappa}{D t}=\vec{\nabla} \cdot\left[\left(\mu+\frac{\mu_{t}}{\sigma_{\kappa}}\right) \vec{\nabla} \kappa\right]+P_{\kappa}-Y_{\kappa}-\frac{\mu}{\epsilon \rho} \kappa \\
& \rho \frac{D \tau}{D t}=\vec{\nabla} \cdot\left[\left(\mu+\frac{\mu_{t}}{\sigma_{\tau}}\right) \vec{\nabla} \tau\right]+P_{\tau}-Y_{\tau}-\frac{\mu}{\epsilon \rho} \tau
\end{aligned}
$$

\section{Results}

The analysis of the heat pipe friction factors was performed by selecting a base case and defining variations. The base cases was defined using the design parameters given in Table 1. The densities, enthalpy of vaporization, and liquid viscosity were evaluated using correlations developed by Fink and Leibowitz [7]. The vapor viscosity was evaluated according a correlation provided by Golden and Tokar [8]. These parameters were selected to fall well within the range of expected operating conditions previously described.

Two sets of tests were performed to evaluate the effect of the wick on friction factors. The first was the impact of permeability. For this test, the base case was simulated assuming a fully saturated wick for both phases, that is, for the impact on the liquid friction factor, it was assumed the wick contained entirely liquid, while for the vapor cases, it was assumed the wick contained

entirely vapor. These conditions represent the extreme bounds during operating conditions and 
Table 1: Design parameters and fluid properties used for the base heat pipe

\begin{tabular}{ll} 
Parameter & value \\
\hline Working fluid & Sodium \\
Power & $4 \mathrm{~kW}$ \\
Inner Diameter & $10 \mathrm{~mm}$ \\
Gap thickness & $0.5 \mathrm{~mm}$ \\
Wick thickness & $0.2 \mathrm{~mm}$ \\
liquid density & $731.5 \mathrm{~kg} / \mathrm{m}^{3}$ \\
liquid viscosity & $1.533\left(10^{-4}\right) \mathrm{kg} / \mathrm{m}-\mathrm{s}$ \\
vapor density & $0.394 \mathrm{~kg} / \mathrm{m}^{3}$ \\
vapor viscosity & $1.991\left(10^{-5}\right) \mathrm{kg} / \mathrm{m}-\mathrm{s}$ \\
enthalpy of vaporization & $3838 \mathrm{~kJ} / \mathrm{kg}$
\end{tabular}

were selected as they would enhance the impact of the permeability.

The saturation level of the wick was tested in the second set of cases. This corresponds directly to the local volume fraction in the heat pipe. For the liquid cases, wick thicknesses between $1 \%$ and $100 \%$ of the gap thickness were tested. For the vapor, thicknesses of only between $1 \%$ and $10 \%$ of the vapor core radius were tested as these represent the anticipated range of wick sizes.

\subsection{Impact of wick permeability}

The first series of cases were performed to evaluate the effect of the wick permeability on the friction factors for both the liquid gap region and the vapor core. These were performed at the minimum value of vapor volume fraction for the liquid cases, and the maximum value for the vapor cases. For the parameters given in Table 1 , these values are $\alpha_{v, \min }=0.74$ and $\alpha_{v, \max }=0.81$. The range of wick permeabilities tested varies between $10^{-5}-10^{-3} \mathrm{~mm}^{2}$. This range is based on values reported by Dunn and Reay [9] for various wick materials including hardware cloth wire meshes and metallic foams.

\section{Liquid region}

The effect of the wick permeability was tested using the previously described model in Nek5000 for laminar flow. For the stated conditions, an equivalent flow through an annulus results in a Reynolds number of 455 , which leads to the value of the nominal friction factor of $f_{0}=0.211$. Seven values of permeability were simulated and the results are shown in Figure 2. The results have been fit with a power law curve, corresponding to the equation

$$
\frac{f}{f_{0}}=\left(1+A \epsilon^{n}\right)
$$

where the coefficients are defined as $A=-6.142$ and $n=0.503$. A power law was chosen both because it fits the data well, and because it preserves the expected limiting behavior as permeability 
approaches zero. For low permeability, it can be seen that the effect of the wick is quite small, however for a highly permeable wick the effects can be quite significant.

Friction factor in the gap

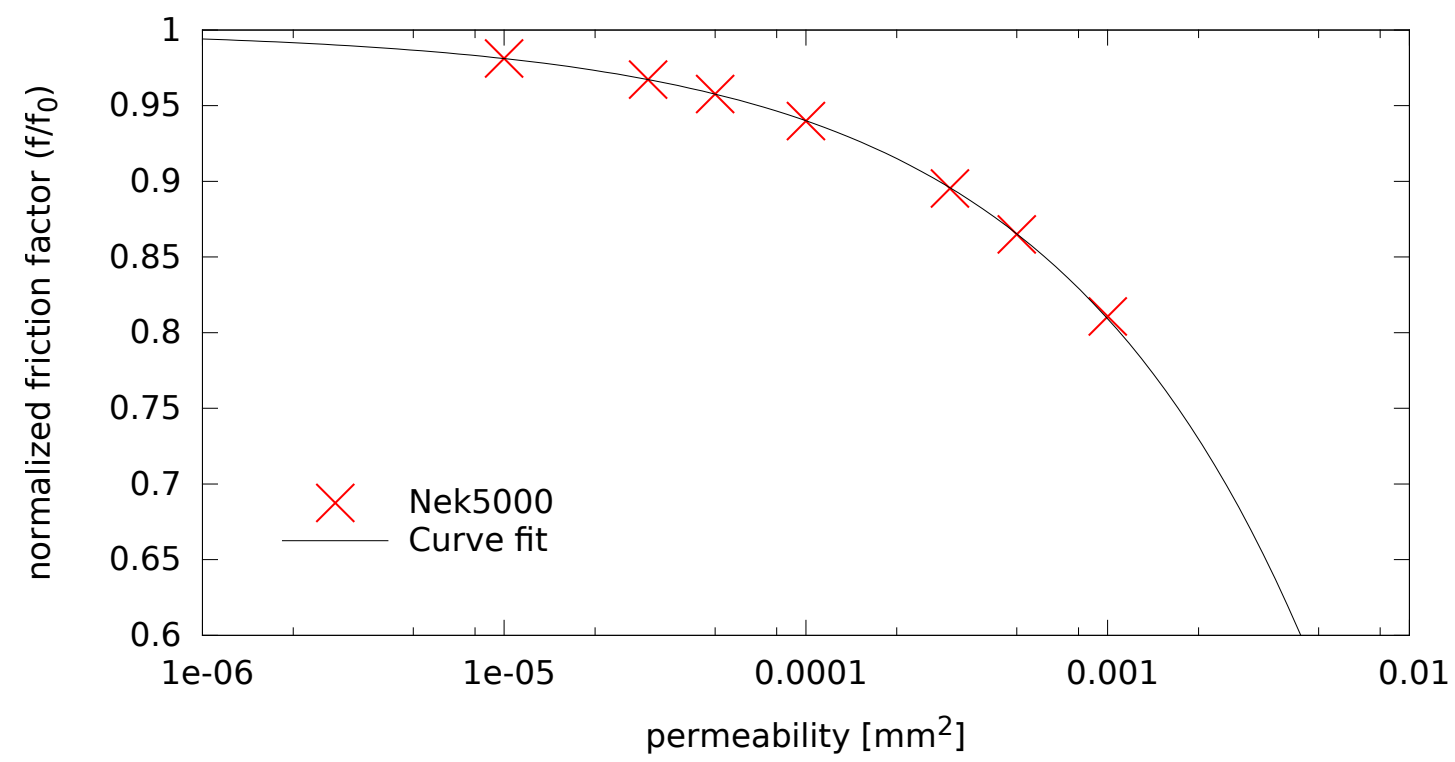

Figure 2: Effect of wick permeability on friction factor for the liquid flow through the gap

Velocity profiles of the liquid through the gap and in the wick are shown in Figure 3. Results are shown for three characteristic values of permeability along with the result for a totally impermeable wick, i.e. a simple annulus, for comparison. As expected, a typical laminar distribution in obtained for the impermeable wick. The effect of increasing permeability can be clearly seen in the velocity profiles. For low permeability, the velocity distribution remains similar to the simple annulus. As the permeability decreases, more flow moves through the wick itself. This effectively acts to increase the available flow area, decreasing the overall pressure drop.

\section{Vapor core}

The effect of the wick on the vapor was tested using the previously described model in Nek5000 for turbulent flow. For the stated conditions, an equivalent flow through a pipe with a radius equal to the inner wick radius $\left(R_{w i}\right)$ has a Reynolds number of 7750 . This gives a value of $f_{0}=0.0356$ for the nominal friction factor. This value was obtained by simulating the equivalent pipe with Nek5000, however it could also be obtained using any of the standard correlations. As with the liquid, multiple values of wick permeability were simulated and the results are shown in Figure 4. A similar power law curve as given by Eq. (12) was fit with the coefficients $A=57.06$ and $n=0.660$. Again, the power law fits the data well and preserves the limiting behavior for an impermeable wick. Unlike the liquid region, however increasing the permeability acts to increase the friction factor. 


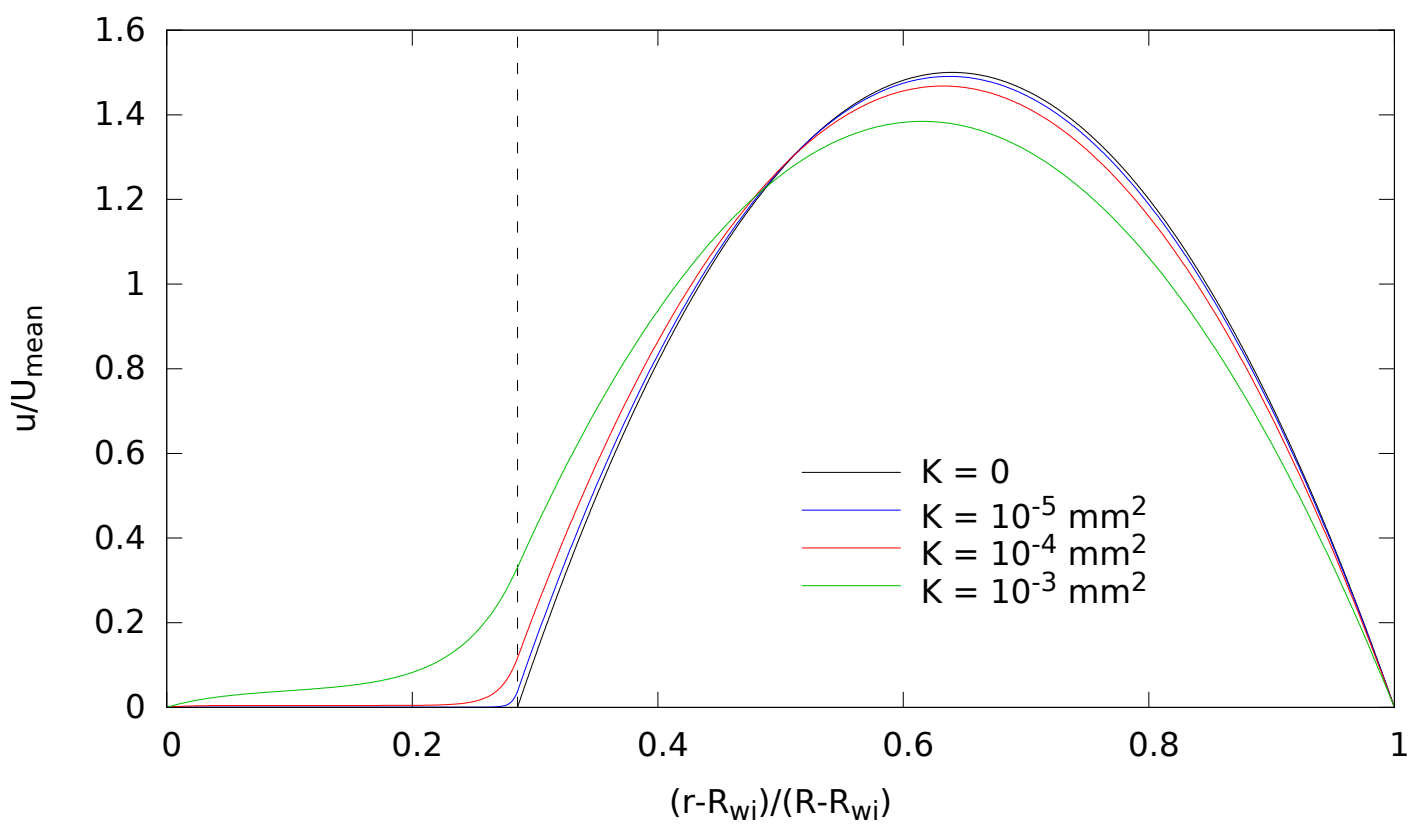

Figure 3: Velocity profiles predicted for the liquid flow through the gap. The vertical dashed line indicates the extent of the wick

Friction factor in the vapor core

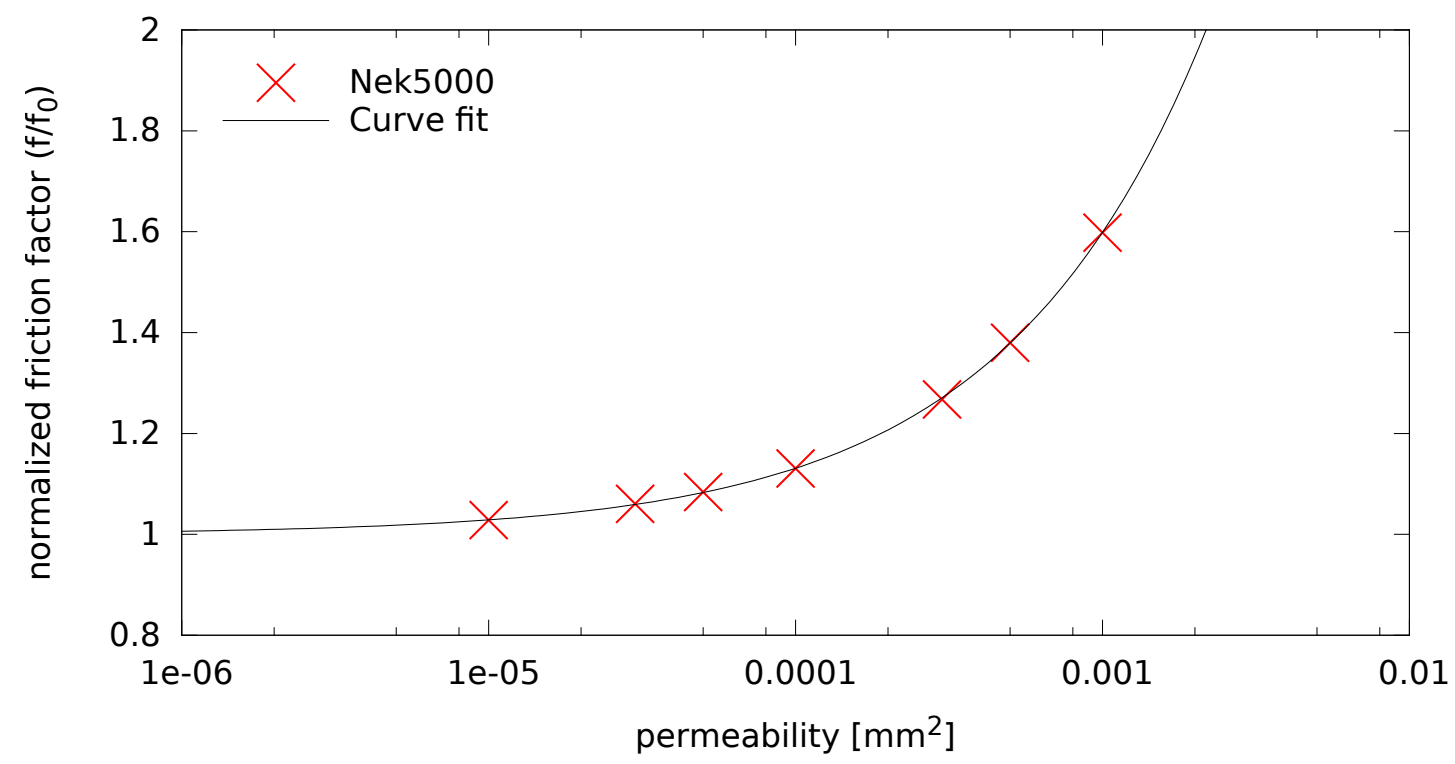

Figure 4: Effect of wick permeability on friction factor for the vapor flow through the core 
The velocity profiles across the vapor core and into the wick are shown in Figure 5. A typical turbulent velocity profile is observed for the impermeable wick case. Similar to what was observed with the liquid flow, at low permeability, the velocity profiles remain similar to the impermeable case and again, as permeability is increased, significant vapor flow is observed in the wick. However, unlike the liquid the predicted friction factor increases, despite the additional available flow area. This can be explained by examining the effect of turbulence.

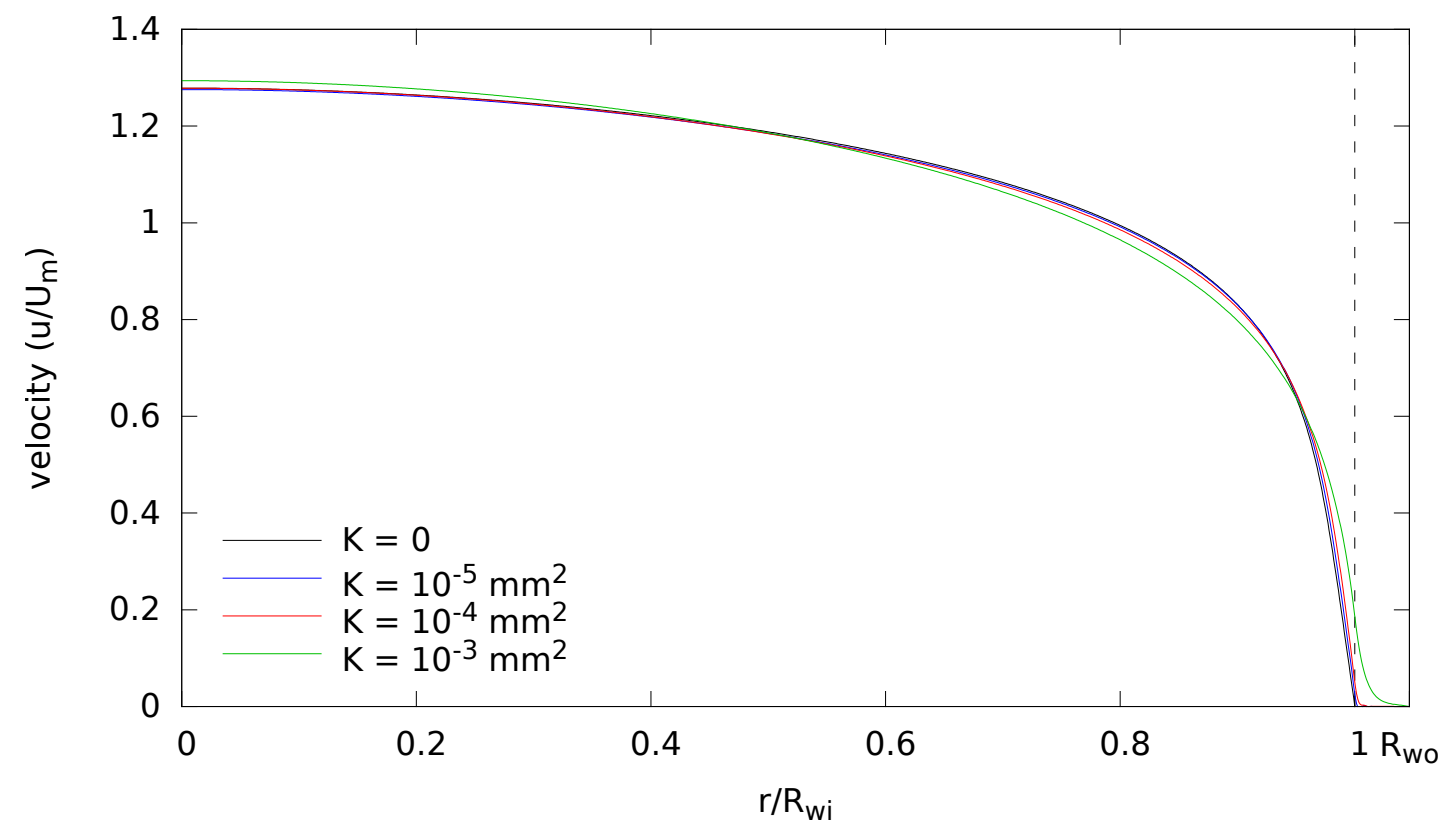

Figure 5: Velocity profiles predicted for the vapor flow through the core. The vertical dashed line indicates the extend of the wick.

The profiles for the turbulence quantities are plotted in Figure 6. Profiles for turbulent kinetic energy, the period of turbulent dissipation, and the ratio of eddy viscosity to laminar viscosity are shown. It can be seen that for the lowest permeability case, $K=10^{-3} \mathrm{~mm}^{2}$, significant levels of both turbulent kinetic energy and dissipation period persist into the wick. This results in a significant eddy viscosity with a sharp velocity gradient, increasing the shear stress. The wick is effectively acting like a wall-roughness, increasing the friction. For higher permeability, the effect is less pronounced, leading a lower permeability acting as a decreased roughness, until the condition of a smooth wall is met with a fully impermeable wick.

As a simple method of verification for the interpretation of increased wall roughness, the required roughness to produce an equivalent friction factor is calculated. For the lowest permeability, the friction factor calculated by Nek5000 is $f=0.057$. Using the Colebrook Equation, which is based on the Moody Charts [10],

$$
\frac{1}{\sqrt{f}}=-2 \log \left(\frac{\varepsilon}{3.71 D_{w o}}+\frac{2.51}{R e_{e q} \sqrt{f}}\right)
$$




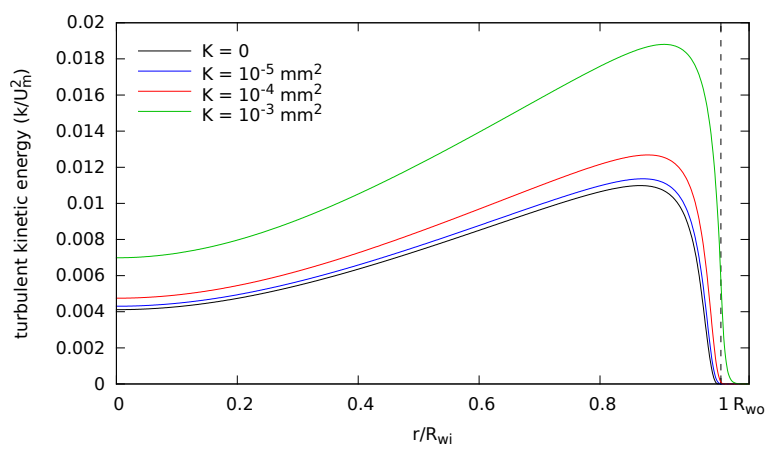

(a) turbulent kinetic energy

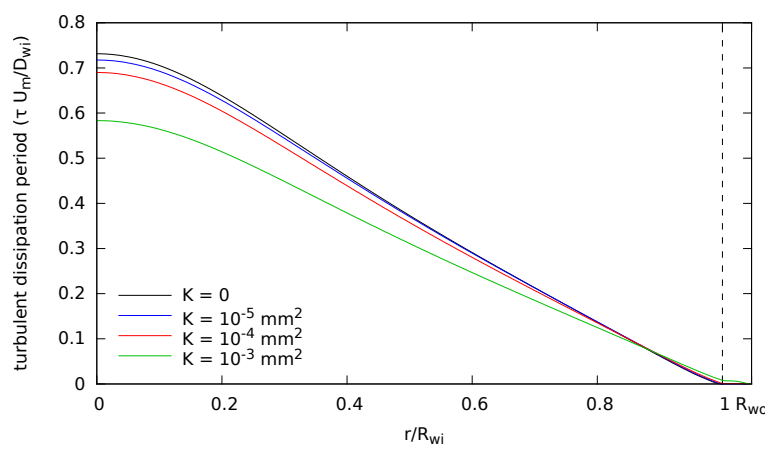

(b) turbulent dissipation period

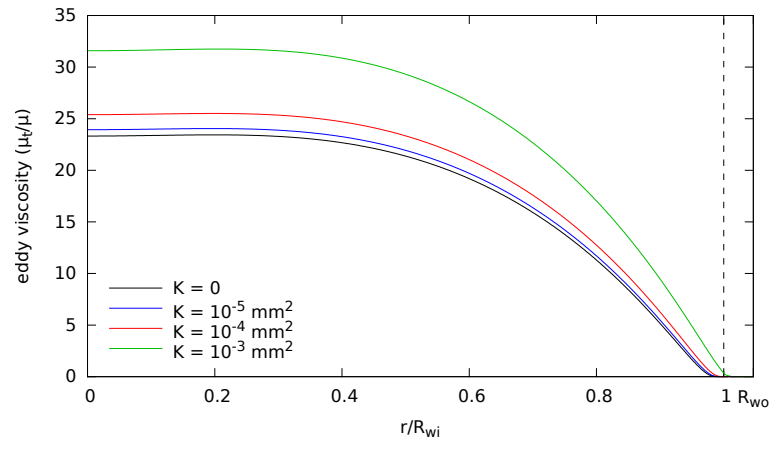

(c) eddy viscosity

Figure 6: Turbulent quantity profiles predicted for the vapor flow through the core. The vertical dashed line indicates the extent of the wick.

The outer wick diameter is used to account for the increased flow area and the equivalent Reynolds number is

$$
R e_{e q}=\frac{4 \dot{m}}{\pi D_{w o} \mu_{g}}
$$

This yields a required roughness of about $\varepsilon=0.24 \mathrm{~mm}$, which is coincidentally on the order of the thickness of the wick, but not an unreasonable value. For a wick of higher permeability, the equivalent roughness will be smaller.

\subsection{Impact of wick saturation}

As a second set of tests, the impact of the location of the liquid/vapor interface in the wick was tested. It is important to note at this point that the location of the interface is assumed to have a zero velocity, so varying the location of the interface within the wick becomes identical to varying the portion of the domain occupied by the wick. Applying a zero velocity boundary condition at the location of the interface is based on the assumption that all of the liquid travels towards the evaporator and all of the vapor travels towards the condenser. However, from previous CFD analysis, this may not necessarily be the case [2]. Two values of permeability where tested for both 
the liquid and vapor regions.

\section{Liquid region}

For the combined liquid flow through the wick and the gap between the wick and the heat pipe wall, simulations were performed for a relative wick thickness of $1 \%$ to $100 \%$ of the gap thickness, $\delta_{w}=R-R_{w o}$. This corresponds to a range of vapor volume fractions of $0.64 \leq \alpha_{v} \leq 0.81$. Overall results for the normalized friction factor for the liquid flow are shown in Figure 7. It can be observed that increasing the thickness of the wick region exposed to liquid, which correlates to a decreasing vapor volume fraction, initially results in a decrease in the friction factor. However, above a certain threshold, the friction factor becomes relatively insensitive. This threshold seems to be higher for more permeable wicks, with the threshold value being at or below a wick-to-gap thickness ratio of 0.1 for $K=10^{-4} \mathrm{~mm}^{2}$ and around 0.2 for $K=10^{-3} \mathrm{~mm}^{2}$. For the higher permeability, the friction factor seems to continue to drop steadily.

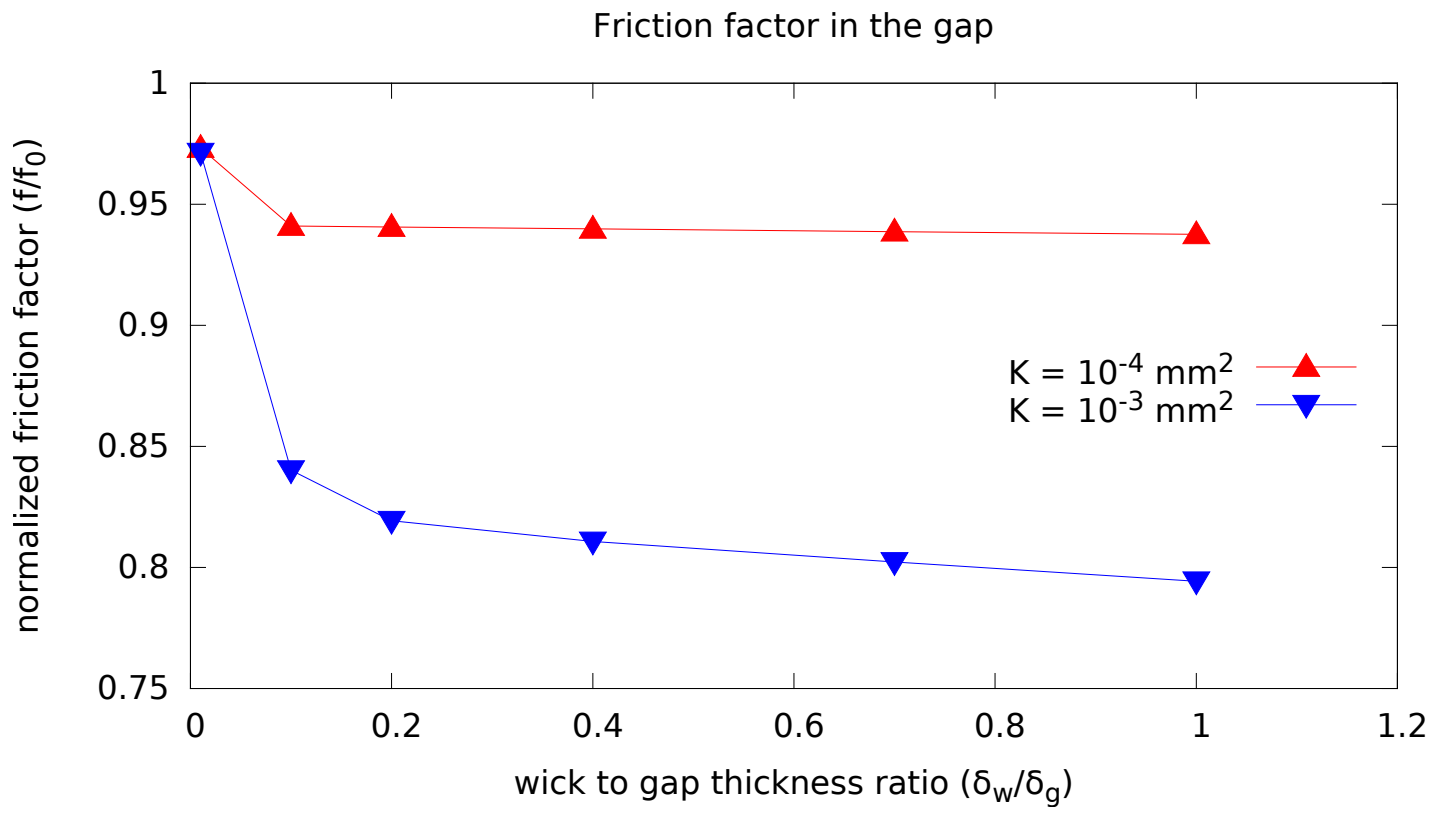

Figure 7: Effect of wick saturation on friction factor for the liquid flow through the gap

The reason for the threshold behavior can be seen in the velocity profiles, presented in Figure 8 . A transition region can be observed between the open flow in the gap and the porous media flow in the wick. For the higher value of permeability, the liquid flow in the wick is significant throughout, whereas for the less permeable wick, the flow is negligible beyond this transition region. For the less permeable wick, once the wick becomes thick enough to include the entire transition region, further increasing it no longer has any effect on the velocity distribution. 


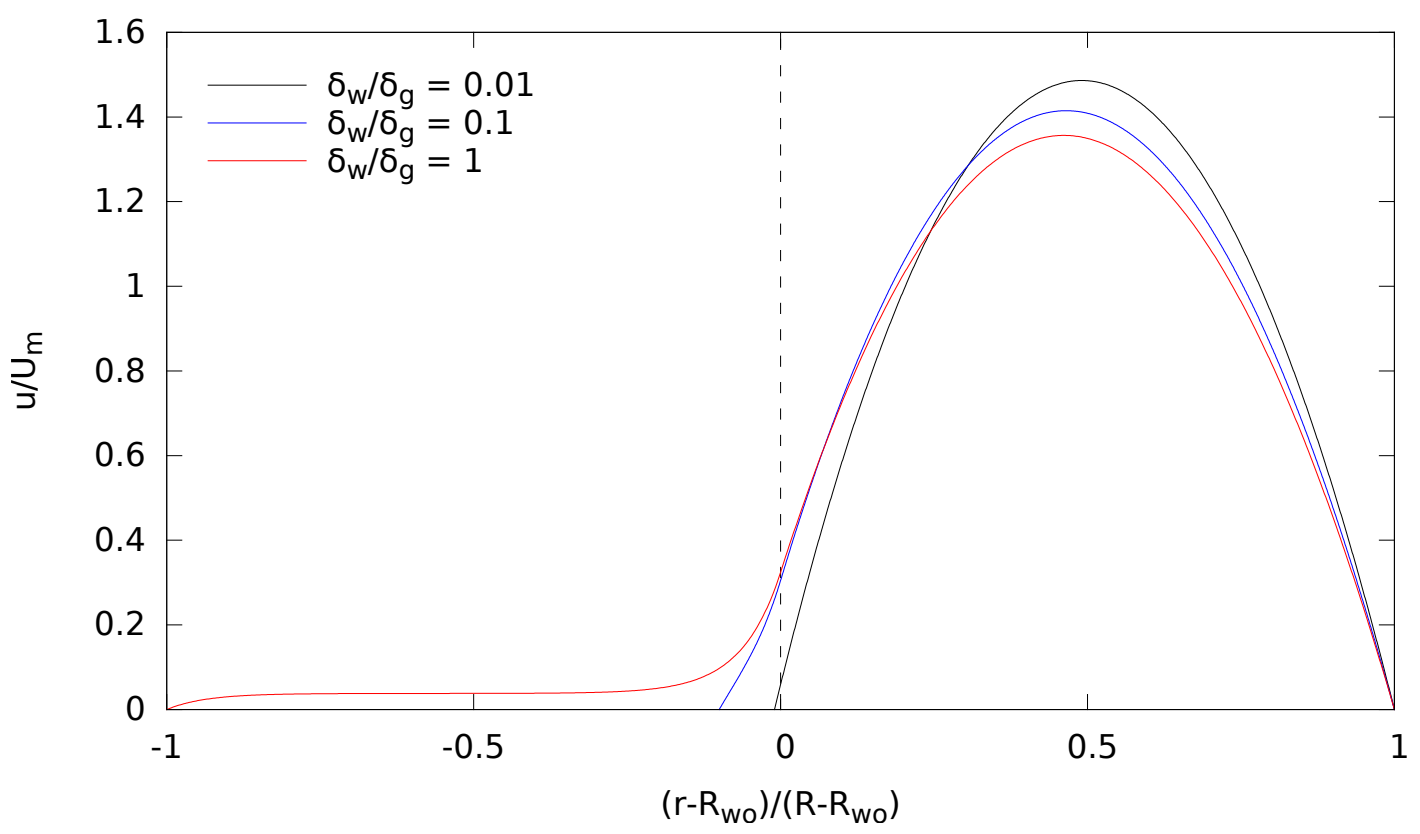

(a) $K=10^{-3}$

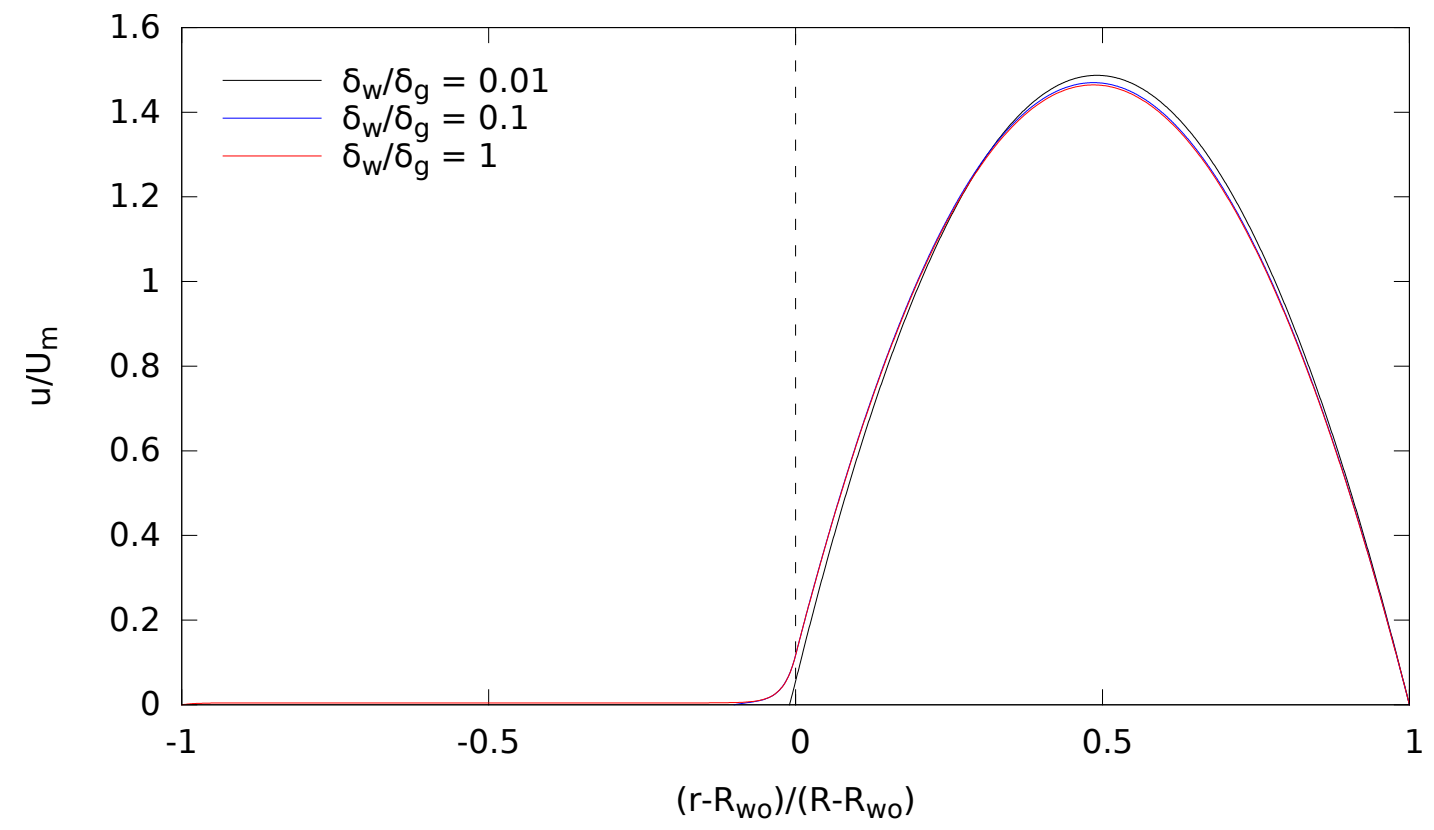

(b) $K=10^{-4}$

Figure 8: Velocity profiles for the liquid flow through the gap for various wick saturation values 


\section{Vapor core}

For the flow in the vapor core, the wick thicknesses investigated were proportionally lower compared to the liquid flow. This is due to the considerably larger area occupied by the vapor core. The investigated thicknesses range from $1 \%$ to $10 \%$ of the inner wick radius, $R_{w i}$. This corresponds to a range of vapor volume fractions of $0.75 \leq \alpha_{v} \leq 0.89$ Results for the normalized friction factor for the vapor flow are shown in Figure 9. Similar threshold behavior is observed in the vapor flow as was seen in the liquid flow. For the lower permeability value, $K=10^{-4} \mathrm{~mm}^{2}$, the effect is even more pronounced than it was in the liquid. Even at a relative thickness of $1 \%$, the normalized friction factor remains practically constant. There is some effect seen for the higher permeability wick, where for relative thicknesses below $4 \%$ the friction factor decreases back to the value for an equivalent smooth pipe.

Friction factor in the vapor core

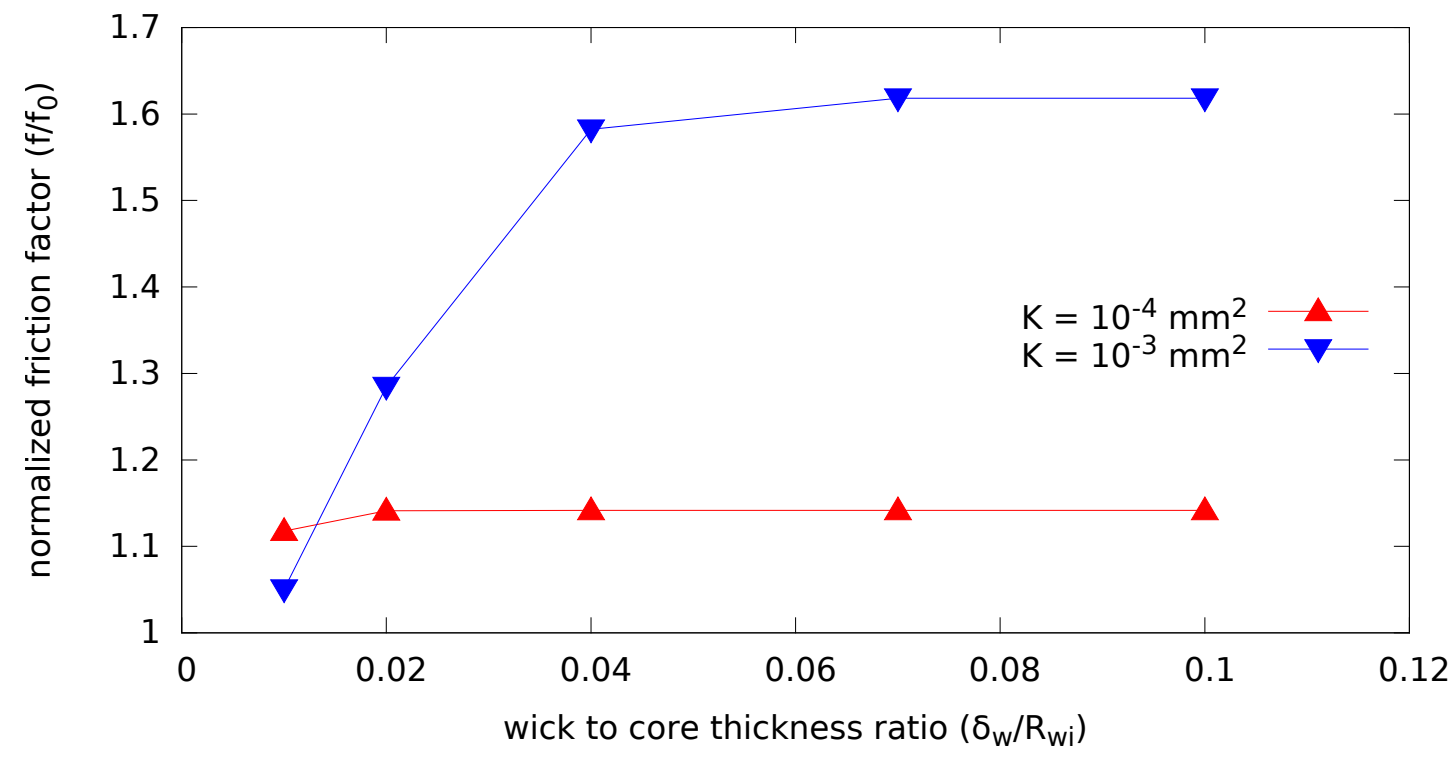

Figure 9: Effect of wick saturation on friction factor for the vapor flow through the core

The thresholding behavior again can be seen from the velocity profiles shown in Figure 10. A transition region is observed at the edge of the wick, and once the wick is thick enough to include the entire region, the thickness no longer impacts the friction factor. For the turbulent flow in the vapor core, the transition region is comparatively thinner compared to the laminar flow in the liquid, particularly where the wick is less permeable. This can be seen as there are some differences in velocity profiles for $K=10^{-3} \mathrm{~mm}^{2}$, but practically none for $K=10^{-4} \mathrm{~mm}^{2}$.

The effect is even more pronounced in the turbulent scalars, which are presented in Figures 11 and 12. Similar to the results observed in the permeability study, the turbulent scalars are transported into the wick for the high permeability case, but only negligibly so for the low permeability case. For the high permeability cases, there are significant differences between the 


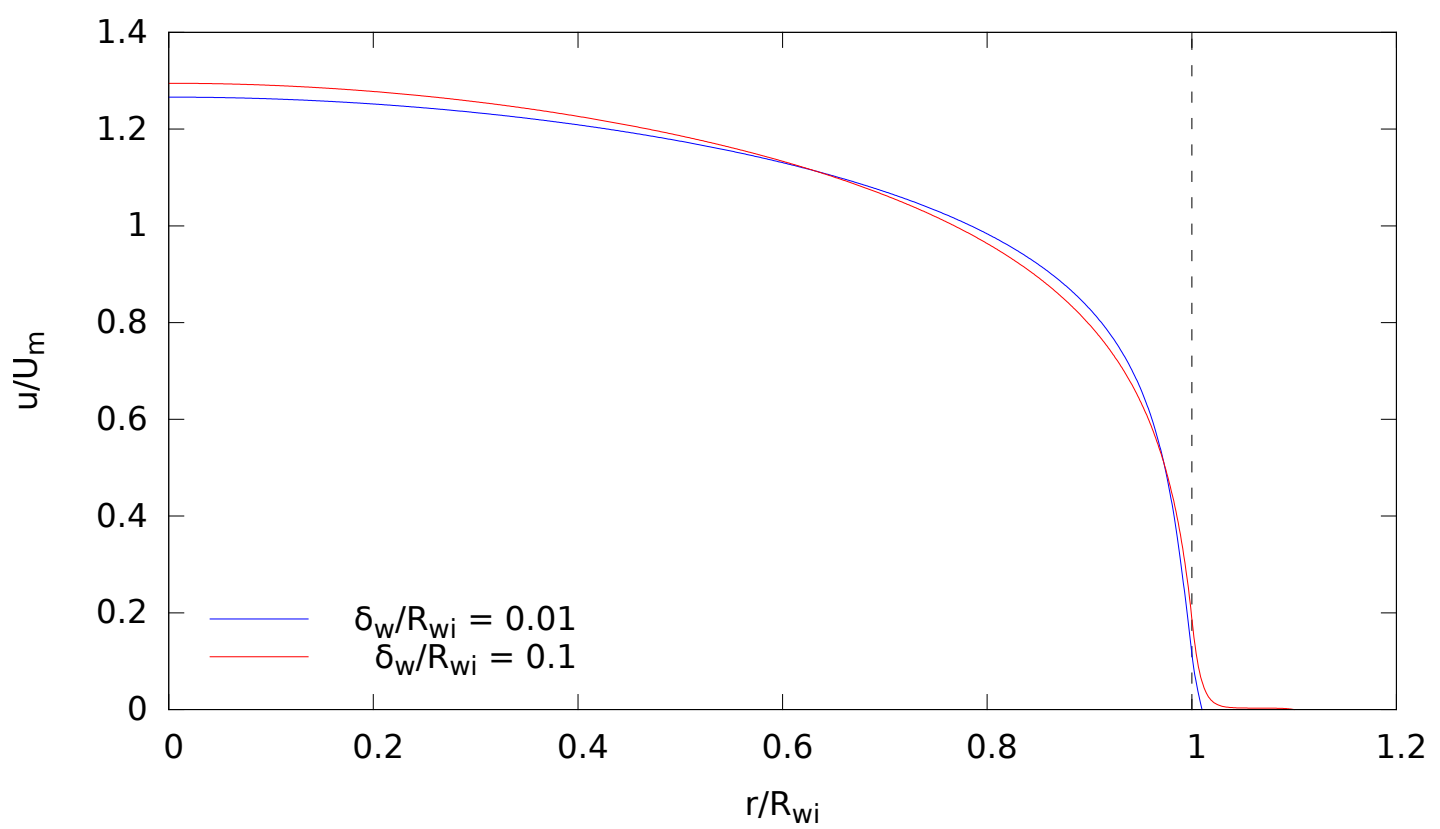

(a) $K=10^{-3}$

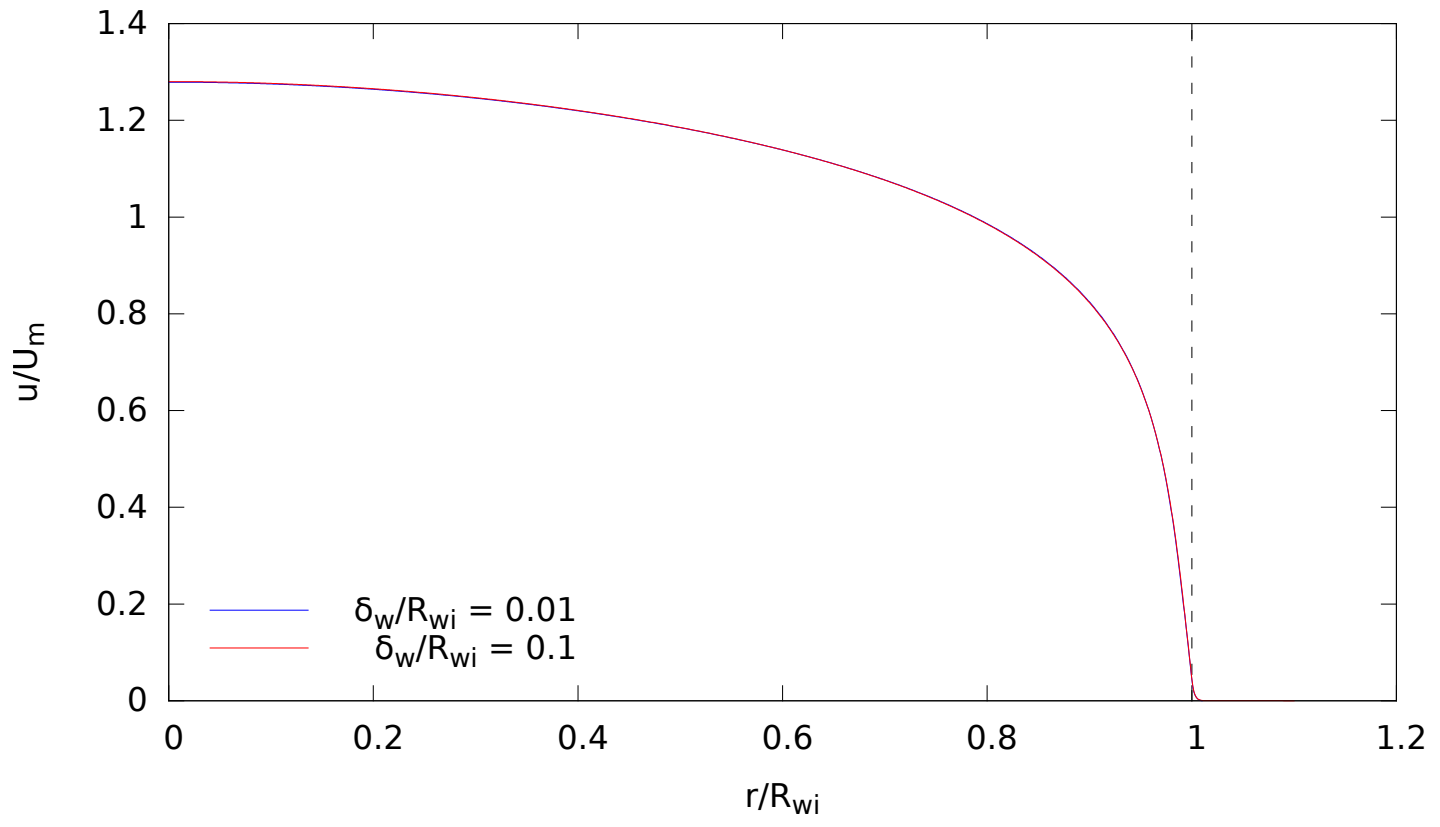

(b) $K=10^{-4} \mathrm{~mm}^{2}$

Figure 10: Velocity profiles for the vapor flow through the core for various wick saturation values 
turbulent scalar profiles. The case with a $10 \%$ wick thickness is able to include the entire transition region at the wick interface, while the thinner wick case is not. It can be seen that the turbulent kinetic energy and eddy viscosity are significantly higher in the $10 \%$ case, leading to the overall increase in friction factor compared to the $1 \%$ case. For the low permeability cases, the turbulent scalars practically do not penetrate into the wick at all, and only very minor differences are observed between cases with different wick thickness.

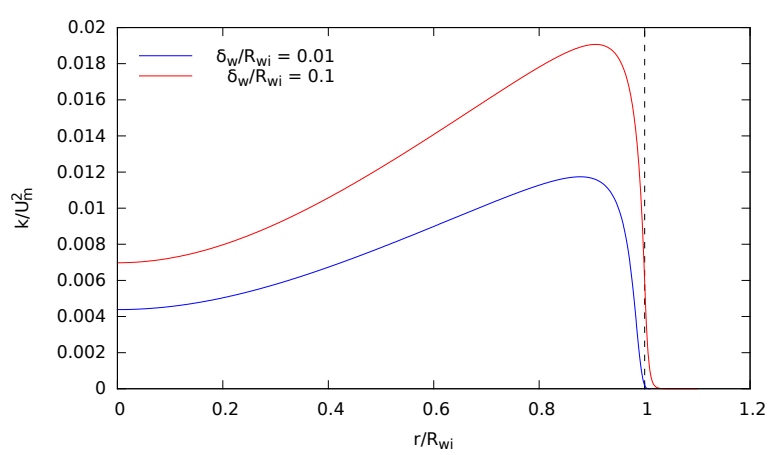

(a) turbulent kinetic energy

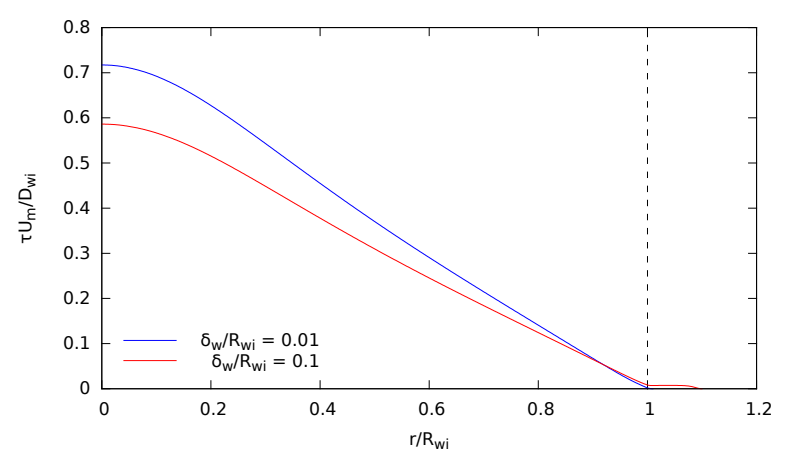

(b) turbulent dissipation period

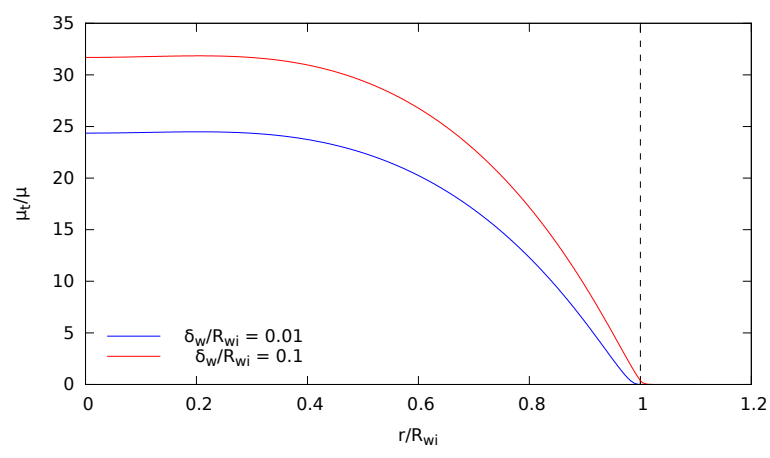

(c) eddy viscosity

Figure 11: Turbulent quantity profiles predicted for the vapor flow through the core for varying wick saturation and high permeability $\left(K=10^{-3} \mathrm{~mm}^{2}\right)$.

Although it is estimated that for standard operation, the liquid/vapor interface should be located very near to the inner surface of the wick, smaller values for the relative wick thickness were not investigated. This is due to the assumed boundary conditions for both velocity and the turbulence scalars. As the wick becomes thinner, the boundary conditions have a stronger impact on the overall solution. However, due to the presence of the liquid/vapor interface, the assumed zero Dirichlet boundary conditions for velocity and both turbulent scalars is unlikely to be accurate. 


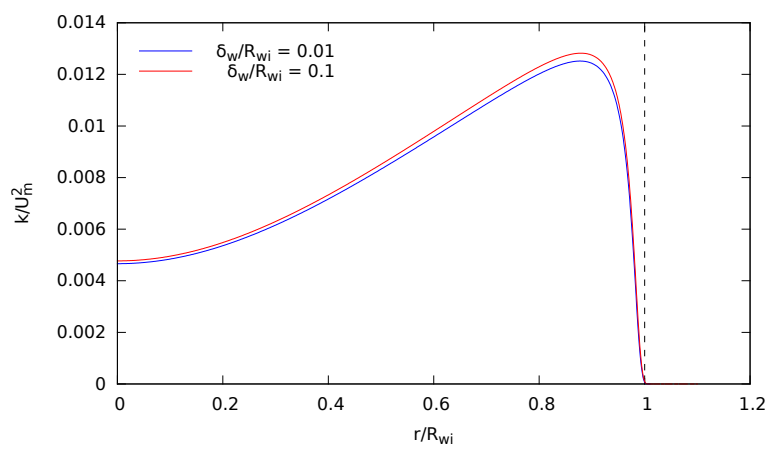

(a) turbulent kinetic energy

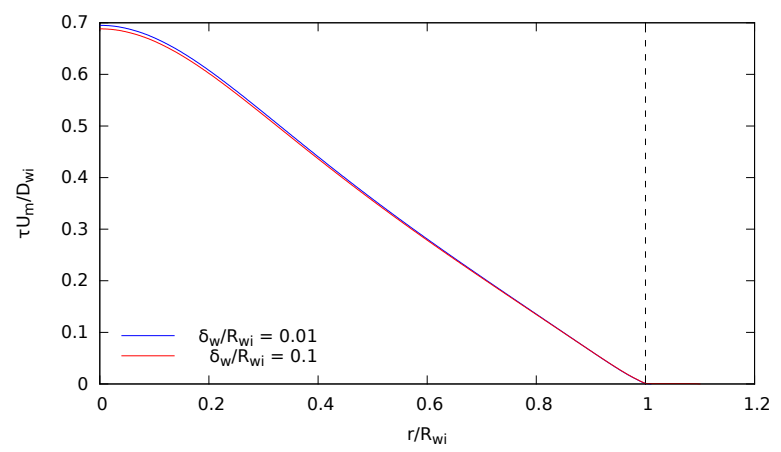

(b) turbulent dissipation period

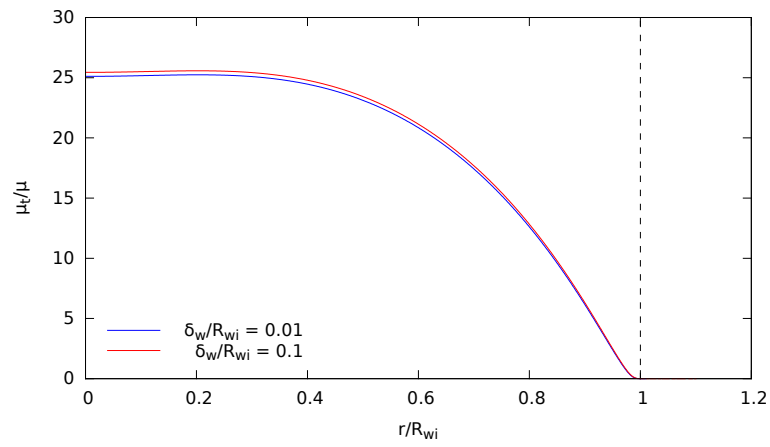

(c) eddy viscosity

Figure 12: Turbulent quantity profiles predicted for the vapor flow through the core for varying wick saturation and low permeability $\left(K=10^{-4} \mathrm{~mm}^{2}\right)$.

\section{Summary and Conclusions}

Two sets of parametric tests accounting for the effect of the wick on friction factors in a sodium heat pipe under standard operating conditions have been performed. The first set deals directly with the permeability of the wick. This test showed that for the laminar flow of liquid metal within the wick and in the gap between the wick and the outer heat pipe wall, the friction factor decreases with increasing wick permeability. This is explained as the expected effect of the wick adding extra flow area for the liquid. For the turbulent flow in the vapor, however, the opposite was observed. Increasing the wick permeability actually increased the predicted friction factor. This is explained as the wick acting like a rough wall, with lower permeability correlating to reduced roughness.

In the second set of tests, the location of the liquid/vapor interface within the wick was varied. This was accounted for in the model as the thickness of the wick exposed to each phase. Two values of permeability were used in these tests. They showed that a transition region exists between the flow in the open region, i.e. the gap for the liquid and the core for the vapor, and the wick. Once the wick is thick enough to fully encompass this transition region, there is little effect from further increasing the wick thickness. This applies to both the liquid and vapor, despite the wick decreasing the liquid friction factor and increasing the vapor friction factor. For less permeable wicks, this 
transition region was shown to be narrower compared to a more permeable wick.

\section{Acknowledgments}

Argonne National Laboratory's work was supported by the U.S. Department of Energy, Office of Nuclear Energy, Nuclear Energy Advanced Modeling and Simulation (NEAMS) program, under contract DE-AC02-06CH11357. 


\section{References}

[1] J. E. Hansel, R. A. Berry, D. Andrs, and R. C. Martineau, "Sockeye theory manual," Tech. Rep. INL/EXT-19-54395, Idaho National Laboratory, Idaho Falls, ID, 2019.

[2] D. R. Shaver and A. Tentner, "Initial evaluation of Nek-2P for modeling of liquid metal heat pipes," Tech. Rep. ANL/NSE-19/42, Argonne National Laboratory, Lemont, IL, 2019.

[3] D. R. Shaver, R. Hu, P. Vegendla, L. Zou, and E. Merzari, "Initial industry collaborations of the center of excellence," Tech. Rep. ANL/NSE-19/15, Argonne National Laboratory, Lemont, IL, 2019.

[4] J. Benton, G. Kalitzin, and A. Gould, "Application of two-equation turbulence models in aircraft design," in 34th Aerospace Sciences Meeting and Exhibit.

[5] A. Tomboulides, S. M. Aithal, P. F. Fischer, E. Merzari, A. V. Obabko, and D. R. Shaver, "A novel numerical treatment of the near-wall regions in the $k-\omega$ class of rans models," Intl. J. Heat and Fluid Flow, vol. 72, pp. 186-199, 2018.

[6] Y. Jin and A. V. Kuznetsov, "Turbulence modeling for flows in wall bounded porous media: An analysis based on direct numerical simulations," Physics of Fluids, vol. 29, no. 045102, 2017.

[7] J. K. Fink and L. Leibowitz, "Thermodynamic and transport properties of sodium liquid and vapor," Tech. Rep. ANL/RE-95/2, Argonne National Laboratory, 1995.

[8] G. H. Golden and J. V. Tokar, "Thermophysical properties of sodium," Tech. Rep. ANL-7323, Argonne National Laboratory, 1967.

[9] P. D. Dunn and D. A. Reay, Heat Pipes. Oxford: Pergamon, 4th ed., 1994.

[10] D. Kaminski and M. Jensen, Introduction to Thermal and Fluids Engineering. Hoboken, NJ: John Wiley \& Sons, 1st ed., 2005. 


\section{Argonne}

Nuclear Science and Engineering Division

Argonne National Laboratory

9700 South Cass Avenue, Bldg. 208

Argonne, IL 60439

www.anl.gov 